\title{
The Application Research with Particle Swarm Bacterial Foraging Intelligent Algorithm in Ship Collision Avoidance
}

\author{
Liu Hongdan \\ College of Automation \\ Harbin Engineering University \\ Harbin, China \\ Zhang Lanyong \\ College of Automation \\ Harbin Engineering University \\ Harbin, China
}

\begin{abstract}
Bacterial foraging algorithm has defects of low convergence rate and high computation complexity, so it will increase the optimization time when used to produce ship collision avoidance path. In order to improve the optimization performance, this paper proposes that intelligent bacterial foraging algorithm of particle swarm can be used for ship collision avoidance, for optimization of collision avoidance path, and for shortening of the generation time of collision avoidance strategies. Besides, it also verifies effectiveness and superiority of this algorithm when it is used to generate ship collision avoidance path under three ship approach situations including head-on-head, crossover, and overtaking through the ship collision avoidance simulation interface designed by VS2010 development environment. This has provided timely and effective information for collision avoidance operation of seaman.
\end{abstract}

Key word: ship collision avoidance ; collision risk; route optimization ; hybrid optimization algorithm; dynamic simulation

\section{I . INTRODUCTION}

Intellectualization of ship collision avoidance is one of the advanced and hot research issues in the academic circle of international maritime. Fig. 1 shows the implementation process of single ship collision avoidance system; involving reception and integration of collision avoidance information, target tracking, collision risk index analysis, judgment for approach situations, generation of optimized path, and dynamic display of

\author{
Liu Sheng \\ College of Automation \\ Harbin Engineering University \\ Harbin, China \\ Gao Zhengguo \\ College of Automation \\ Harbin Engineering University \\ Harbin, China
}

collision avoidance path. It is a multi-objective and nonlinear planning problem, so it covers research and application of fuzzy logic, neural network (fuzzy neural network), expert system, genetic algorithm, danger model immune algorithm, modified PSOIM, and artificial intelligence technology like subject and case-based reasoning technology in ship collision avoidance field [1-4].

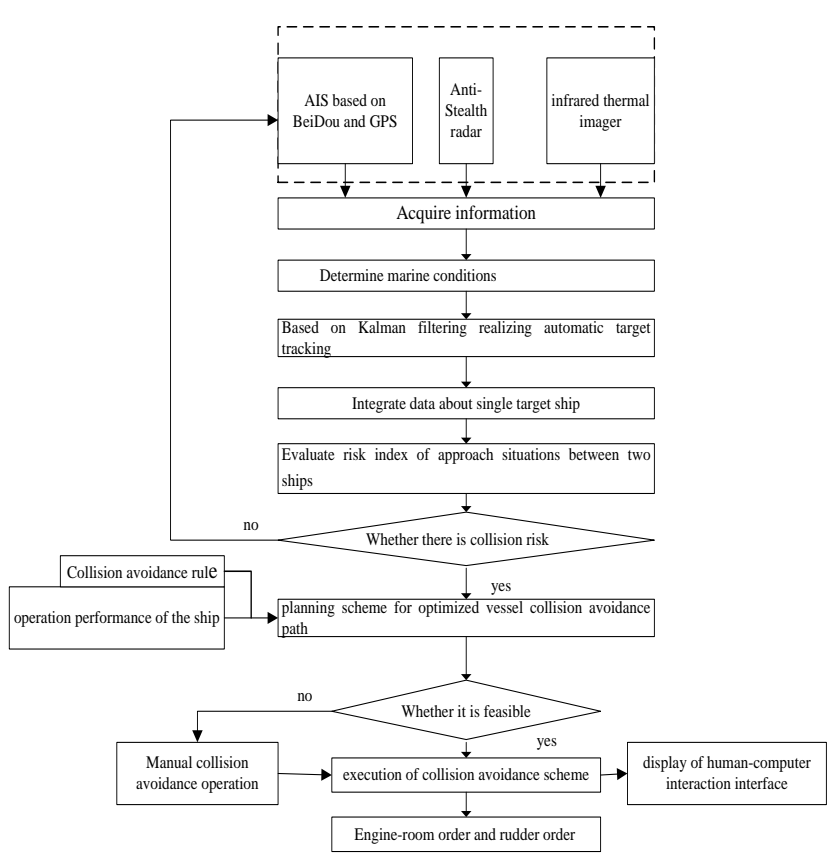

Figure1. Implementation Process of Single Ship Collision Avoidance System

In which bacterial foraging algorithm (BFO) proposed by K. M. Passino in 2002 is a meta-heuristic search algorithm that simulates the foraging behavior of escherichia coli. Compared with other intelligent 
algorithms, this algorithm possesses strong global searching ability, and it can efficiently solve many optimization problems in the real world. In order to overcome defects of this algorithm like slow convergence rate and being caught in precocity and mistakes, it is improved on the basis of particle swarm optimization. In this way, the convergence rate in the bacterial foraging process can be increased ${ }^{[5]}$ and the search time will be shortened without affecting the search quality. Therefore, this paper proposes that the bacterial foraging algorithm of particle swarm optimization can be applied to generation of intelligent ship collision avoidance path. Moreover, effectiveness and superiority of this algorithm in optimization of ship collision avoidance path are verified.

\section{II . COLLISION RISK INDEX}

Collision risk index (CRI) is measurement for the possibility of collision among ships, and its value is $0 \sim 1$ under general situations. $\mathrm{CRI}=0$ means that it is safe between two ships and there is no collision possibility; $\mathrm{CRI}=1$ shows that if no measure is taken, the two ships will inevitably collide, and when the collision risk index exceeds a certain threshold value, some measures must be taken. Parameters related to ship collision risk index include distance of closest point of approach (DCPA) between two ships, time of closest point of approach (TCPA) between two ships, distance between two ships (D), direction of the objective ship(B), and ship velocity ratio $(\mathrm{K})$. In order to consider the above factors, this paper determines CRI among single ships on the basis of CRI of time $\left(U_{t T}\right)$ and CRI of space $\left(U_{d T}\right)$.

$$
\mathrm{CRI}=U_{t T} \oplus U_{d T}
$$

Where $\oplus$ is composition operator, and the operation is defined as:

$$
\begin{aligned}
& U_{d T}=0 \ldots \ldots \text { CRI }=0 ; \\
& U_{d T} \neq 0, U_{t T}=0 \ldots \ldots \ldots . . \mathrm{CRI}=0 ; \\
& U_{d T} \neq 0, U_{t T} \neq 0 \ldots . \mathrm{CRI}=\max \left(U_{d T}, U_{t T}\right) .
\end{aligned}
$$

Therefore, only when CRI of time $\left(U_{t T}\right)$ and CRI of space $\left(U_{d T}\right)$ are not zero, does ship collision risk exist. According to the judgment level of risk index, this paper chooses to call collision avoidance path algorithm to prevent the collision when $\mathrm{CRI}=0.7$ (relatively high).

\section{ESTABLISHMENT FOR OBJECTIVE FUNCTION OF SHIP COLLISION AVOIDANCE}

Suppose that our ship is the give-way ship, and safe collision avoidance should be guaranteed at first and then "economical" collision avoidance must be considered in the process of planning collision avoidance path Therefore, the collision avoidance path optimization algorithm is required to complete collision avoidance in the shortest path on the premise of ensuring safety; the objective function is as follows [5-6].

$$
J=\min \left(d_{s}+d_{r}\right)
$$

Where, $d_{s}$ is the sailing distance of our ship after collision avoidance; $d_{r}$ is the sailing distance of our ship at the resumption stage. Suppose that velocity of our ship is $V$, steering angle of avoidance is $C_{\mathrm{s}}$, steering angle at the resumption stage is $C_{\mathrm{r}}$, and sailing time after avoidance is $t_{a}$. Then $d_{s}$ and $d_{r}$ in the above objective function meet the following expression:

$$
\begin{gathered}
d_{s}=t_{a} * V \\
d_{r}=t_{a} * V * \sin C_{s} /\left|\sin C_{r}\right|
\end{gathered}
$$

In the process of path planning, constraint condition should be provided for variables in Formula (4) and (5), as shown in Formula (6):

$$
\begin{aligned}
& 30^{\circ} \leq C_{s} \leq 90^{\circ} \\
& -60^{\circ} \leq C_{r} \leq-30^{\circ} \\
& t_{C P A 1} \leq t_{a} \leq 40 \mathrm{~min} \\
& d_{C P A 1} \geq d_{G}, d_{C P A 2} \geq d_{G}
\end{aligned}
$$

Where $d_{C P A 1}$ and $d_{C P A 2}$ are the new DCPA after 
collision avoidance and course restoration, and the value of $d_{G}$ is determined by the zero boundary of space risk index. The sailing time after collision avoidance is $t_{a}$, and it should be equal to the new DCPA $t_{C P A 1}$ after collision avoidance behavior is adopted at least. The calculation process for $t_{a}$ is determined according to the actual simulation, as shown in the following:

(1) If $d_{C P A 1}<d_{G}$, then $t_{a}=40 \mathrm{~min}$; thus the objective function will be too large and the optimization process is directly eliminated;

(2) Under the condition of $d_{C P A 1} \geq d_{G}$, if $t_{C P A 1}>0$, then $t_{C P A 1}=t_{a}$ is the starting point; besides, if $d_{C P A 2} \geq d_{G}$ is not satisfied, $t_{a}$ will increase by a certain step value;

(3) Under the condition of $d_{C P A 1} \geq d_{G}$, if $t_{C P A 1}<0$, then the initial value $t_{a}=0.05 * 60$; besides, if $d_{C P A 2} \geq d_{G}$ is not satisfied, $t_{a}$ will increase by a certain step value (search step value adopted by simulation of this paper is equal to $0.02 * 60$ ).

\section{SHIP COLLISION AVOIDANCE PATH STRATEGY BASED} ON BACTERIAL FORAGING ALGORITHM OF PARTICLE SWARM

The implementation process for bacterial foraging algorithm of particle swarm optimization is presented in Fig.2 as in [7]. Parameter determination in the algorithm implementation process includes as in [8] search space dimensionality of bacterial foraging algorithm $P=2$; bacterial quantity used for search $S=26$; and number of convergence $N_{c}=50$; the maximum step of movement is required to be $3-8$, which can guarantee a good search effect as in [9], in this paper, ; and number of replication $N_{r e}=4$; number of migration $N_{e d}=2$; value range of migration possibility should be $0.05-0.3$, and it is $P_{e d}=0.25$ in this paper; In particle swarm optimization, $C_{1}, C_{2}, R_{1}$ and $R_{2}$ are random parameters.

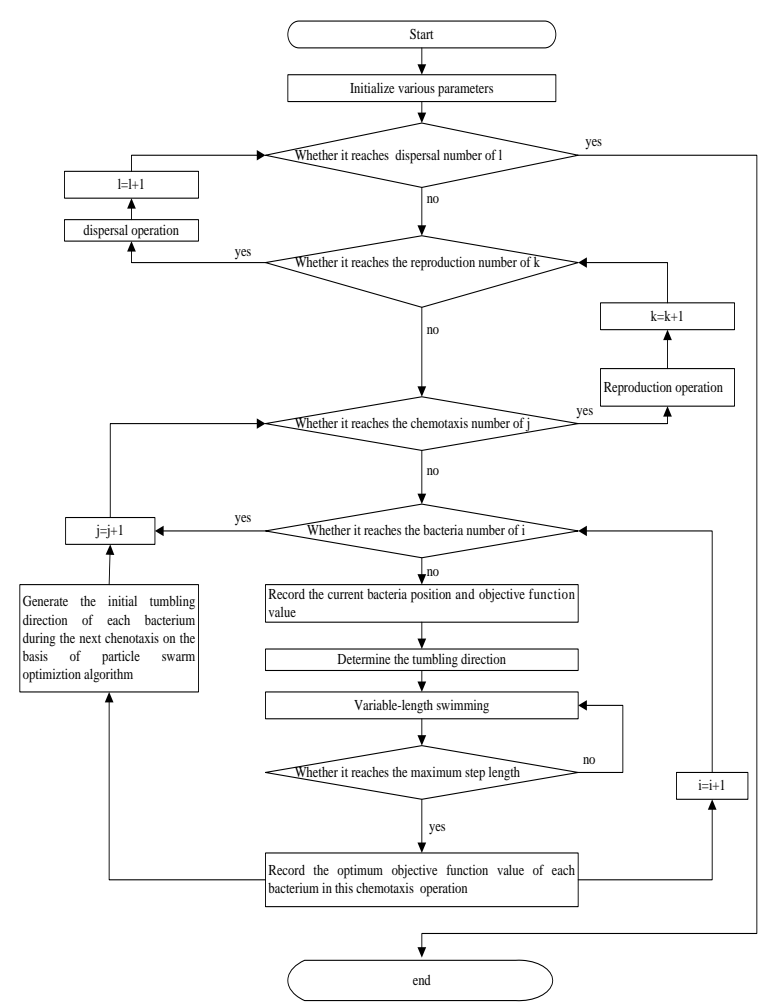

Figure2. Bacterial Foraging Algorithm Process of Particle Swarm Optimization

By combining with Fig. 2, the steps of implementing ship collision avoidance path optimization are as follows:

(1) Initialize parameters, arrays, and positions, and set the initial step $C=0.05$.

(2) Start the circulation process

For(int $\left.l=0 ; l<N_{r e} ; l++\right)$

$$
\text { For (int } k=0 ; k<N_{r e} ; k++ \text { ) }
$$

$$
\text { For (int } j=0 ; j<N_{c} ; j++ \text { ) }
$$

For( int $i=0 ; i<S ; i++$ )

//Initialize the random position of bacteria in $2 \mathrm{D}$ space; $P_{x}=60+30 *\left(2.0 *((\right.$ double $) \operatorname{rand}()) / R A N D \_M A X-1$ $P_{y}=-45+15 *\left(2.0 *((\right.$ double $)$ rand ()$) / R A N D_{-} M A X-1$

//Call livefun function to calculate the initial value of objective function;

$J[l][k][j][i]=$ livefun (Calculate the objective function 
for the shortest ship collision avoidance path, and save the current value of fitness Jlast $=J$ )

// Turn it over in 2D space to generate a random direction Delta $=2 *(($ double $)$ rand ()$) /$ RAND_MAX -1.0

$$
\operatorname{cov}+=\operatorname{pow}(\text { Delta }, 2.0)
$$

//Move toward a new direction within the maximum step range to produce a new $2 \mathrm{D}$ position (steering angle of collision avoidance and resumption) and objective function

$$
P=P+C * \text { Delta } / \text { sqrt }(\mathrm{cov})
$$

$J[l][k][j][i]=$ livefun (objective function)

//Seek the globally optimal solution $P_{g b e s t}$ and single

optimal solution $P_{\text {lbest }}$ as well as the corresponding

particle position during this convergence circulation; calculate the current optimal fitness value Jbest $=J$ // Update the particle state according to particle swarm optimization and select the new direction and position of the next convergence

$V=w^{*} V+C_{1} * R_{1} *\left(P_{\text {lbest }}-P\right)+C_{2} * R_{2} *\left(P_{\text {gbest }}-P\right)$

$$
P=P+V
$$

// Rank the objective function values, and eliminate some bacteria

\section{Quicksort(Jhealth, S)}

// Execute dispersal operation according to migration possibility, gain new random positions in the $2 \mathrm{D}$ space, and execute the next circulation.

\section{VSIMULATION VERIFICATION AND RESULT ANALYSIS}

Dynamic ship collision avoidance simulation is realized via intelligent bacterial foraging algorithm of particle swarm under the interface of $\mathrm{VC}++9.0$ environment based on VS2010 as in [10]. Due to the restriction of display interface, the sailing time is calculated when CRI is greater than 0.4.

(1) Under head-on-head approach of single ship, initial motion parameters of our ship are: $V=14, B=0^{\circ}$, and the coordinate is $(0,0)$; initial motion parameters of the target ship are: $V=15, B=180^{\circ}$, and the coordinate is $(0,3)$. According to collision risk index analysis, $\mathrm{CRI}=1$, $\mathrm{DCPA}=0$, and TCPA $=-0.10$. There is collision risk at the preliminary stage, and the collision avoidance process is implemented directly, as shown in Fig. 3.

(2) Under crossover approach of single ship, initial motion parameters of our ship are: $V=14, B=0^{\circ}$, and the coordinate is $(0,0)$; initial motion parameters of the target ship are: $V=15, B=300^{\circ}$, and the coordinate is $(4,0)$. According to collision risk index analysis, under the initial state of the system, $\mathrm{CRI}=0.45, \mathrm{DCPA}=1.79$, and $\mathrm{TCPA}=-0.25$. After sailing straightly for 1.8 minutes, the collision risk threshold value $\mathrm{CRI}=0.7$ is reached, so the collision avoidance process is implemented, as shown in Fig. 4.

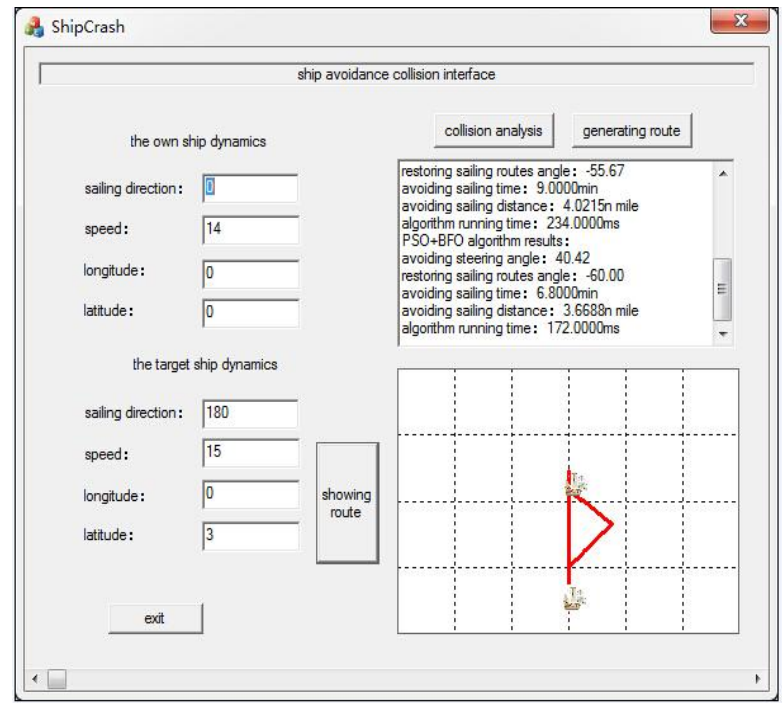

Figure3. Interface for Path Optimization Under Head-on-head Approach

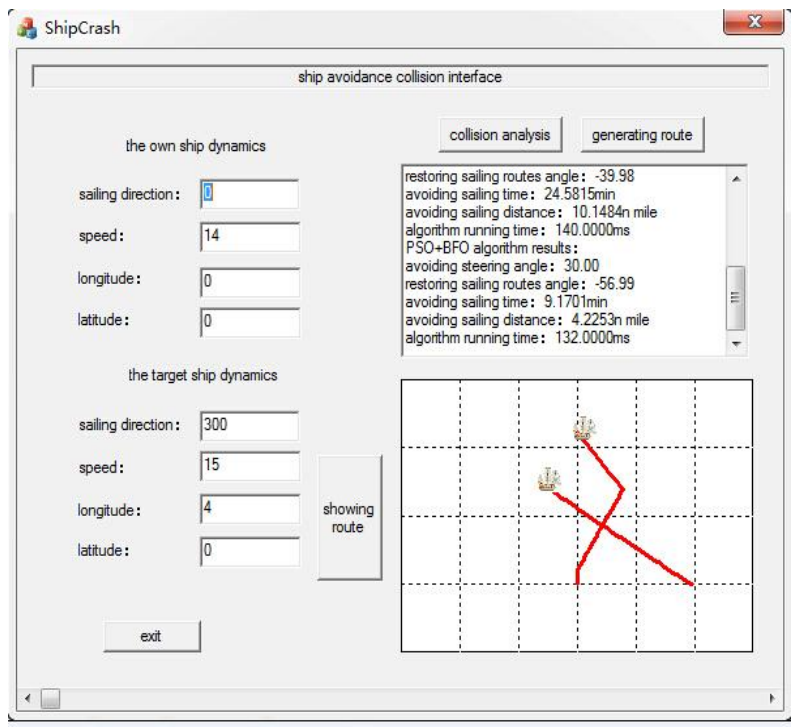

Figure4. Interface for Path Optimization under Crossover Approach

(3) Under overtaking approach of single ship, initial 
motion parameters of our ship are: $V=12, B=0^{\circ}$, and the coordinate is $(0,2)$; initial motion parameters of the target ship are: $V=18, B=0^{\circ}$, and the coordinate is $(0,0)$. According to collision risk index analysis, there is collision risk at the preliminary stage, and the collision avoidance process is implemented directly, as shown in Fig. 5.

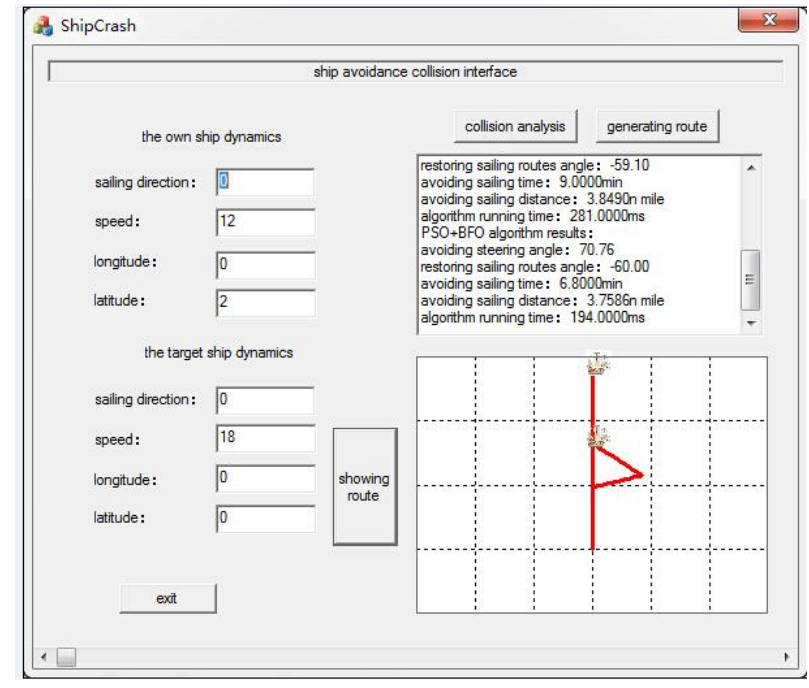

Figure5. Interface for Path Optimization under Overtaking Approach

In the above collision avoidance interfaces, by clicking the path generation buttons, the comparison between bacterial foraging algorithm and intelligent bacterial foraging algorithm of particle swarm in optimized collision avoidance parameters will be presented, as shown in table 1: according to table 1 , on the one hand, intelligent bacterial foraging algorithm of particle swarm can reduce the ship avoidance angle, reasonably select resumption angle of the ship, decrease the sailing time of avoidance, and shorten the sailing distance, so efficiency of intelligent ship avoidance is enhanced. On the other hand, particle swarm optimization can increase the convergence rate and reproduction quality of bacteria, so time taken by the algorithm is obviously decreased. Besides, more collision avoidance time is provided for seaman and the possibility of improper operation is reduced.

\section{VI . CONCLUSION}

Intelligent bacterial foraging algorithm of particle swarm has advantages of strong global searching ability and high local convergence rate. Therefore, this algorithm is applied to optimization of ship collision avoidance strategies in this paper. Besides, the dynamic collision avoidance processes based on this algorithm under three approach situations are demonstrated via VS2010 simulation interface. By displaying the comparison parameters of collision avoidance, feasibility and superiority of applying this algorithm to intelligent ship collision avoidance are verified directly and visually. This has laid a foundation for implementation of multi-ship collision avoidance process in the next step.

TABLE I. Optimized Collision Avoidance Parameters

\begin{tabular}{|c|c|c|c|c|c|}
\hline & $\begin{array}{l}\text { avoiding steering angle } \\
\left(\left(^{\circ}\right)\right.\end{array}$ & $\begin{array}{l}\text { resumption sailing } \\
\text { routes angle } \quad\left({ }^{\circ}\right)\end{array}$ & $\begin{array}{l}\text { Avoiding sailing } \\
\text { time }(\mathrm{min})\end{array}$ & $\begin{array}{l}\text { Avoiding sailing } \\
\text { distance (n mile) }\end{array}$ & $\begin{array}{l}\text { algorithm running } \\
\text { time (ms) }\end{array}$ \\
\hline $\begin{array}{l}\text { BFO } \\
\text { head-on-head }\end{array}$ & 49.08 & -55.67 & 9 & 4.0215 & 234 \\
\hline $\begin{array}{l}\text { PSO+BFO } \\
\text { head-on -head }\end{array}$ & 40.42 & -60 & 6.8 & 3.6688 & 172 \\
\hline BFO crossing & 39.62 & -39.98 & 24.5815 & 10.1484 & 140 \\
\hline $\begin{array}{l}\text { PSO+BFO } \\
\text { crossing }\end{array}$ & 30 & -56.99 & 9.1701 & 4.2253 & 132 \\
\hline $\begin{array}{c}\text { BFO } \\
\text { over-taking }\end{array}$ & 77.62 & -59.10 & 9 & 3.8490 & 281 \\
\hline $\begin{array}{l}\text { PSO+BFO } \\
\text { over-taking }\end{array}$ & 70.62 & -60 & 6.8 & 3.7586 & 194 \\
\hline
\end{tabular}




\section{REFERENCES}

[1] SHI Pingan and LI Yongji, "Artificial Intelligence Application in the field of warships collision avoidance,"Guang Zhou maritime college journals, vol. 2, 2007, pp.1-3, doi:10.1127/science.1066467.

[2] CHEN Xide and LIU Yuan, "Study on Ship Collision Avoidance Trajectory Optimization in Inland Waterways with Genetic Algorithm," Journal of Navigation of China, vol. 2, 2006, pp.38-46,doi:675.96.

[3] BAI Yiming, HAN Xingjie and MENG Xianrao, "Optimization of strategy for Ship Collision Avoidance with Danger Model Immune Algorithm," Journal of Navigation of China, vol. 35(2), 2012, pp.29-32.

[4] TIAN Yubo and PAN Pengpeng, “Application of Improved Immune Particle Swarm Algorithm in Ship Collision Avoidance," Journal of Navigation of China, vol. 34(1), 2011, pp.48-51.

[5] M.D.Nguyen,V.T.Nguyen and H.Tamaru, "Automatic Collision Avoiding Support System for Ships in Congested Waters and at Open Sea,". International conference on Control, Automation and Information Sciences, 2012, pp.96-101, doi: 10.1109/ICCAIS.2012.6466638.

[6] MA Wenyao and YANG Jiaxuan, "Optimization of
Ship Collision Avoidance Route based on Bacterial Foraging Algotithm,'Journal of Da lian Maritime University, vol. 39(2), 2013, pp. 21-24.

[7] ArijitBiswas, SambartaDasgupta, Swagatam Das and Ajith Abraham, "Synergy of PSO and Bacterial Foraging Optimization A Comparative Study on Numerical Benchmarks," Innovations in Hybrid Intelligent Systems, ASC 44, 2007, pp. 255-263, doi:10.1109/WICT.2012.6409165.

[8] Yosra JARRAYA, Souhir BOUAZIZ, Adel M. ALIMI, and Ajith Abraham, "A Hybrid Computational Chemotaxis in Bacterial Foraging Optimization Algorithm for Global Numerical Optimization,” 2013 IEEE International Conference on Cybernetics,pp. 213-218,doi: 10.1109/CYBConf.2013.6617428.

[9] K. M. Passino, "Biomimicry of bacterial foraging for distributed optimization and control," IEEE Control Systems Magazine, vol. 6(2), 2002, pp. 52-67, doi: 10.1109/MCS.2002.1004010.

[10] Xue Yanzhuo, "Automatic Simulation of Ship Navigation in Confined Waterways, D" The University of Strathclyde in ship building and ocean engineering. 2010. 